\title{
A cidade do entretenimento: um estudo sobre a identidade cultural da cidade de São Paulo
}

Entertainment city: a study on the cultural identity of the city of São Paulo La ciudad del entretenimento: un estudio sobre la identidad cultural de la ciudad de São Paulo

http://dx.doi.org/10.18472/cvt.16n1.2016.0935

Alexandre Leonarde 〈aleonarde@uol.com.br >

Pós-doutor em Lazer e Turismo na Escola de Artes, Ciências e Humanidades da Universidade de São Paulo (EACH-USP), Membro do GIEL/USP/CNPq, São Paulo, SP, Brasil.

Ricardo Ricci Uvinha 〈uvinha@usp.br >

Professor livre-docente, supervisor de pós-doutorado e orientador credenciado na pós-graduação em Turismo da Universidade de São Paulo, Líder do GIEL/USP/CNPq, São Paulo, SP, Brasil.

CRONOLOGIA DO PROCESSO EDITORIAL

Recebimento do artigo: 06-mar-2014

Aceite:20-fev-2016

FORMATO PARA CITAÇÃO DESTE ARTIGO

LEONARDE, A.; UVINHA, R. R. A cidade do entretenimento: um estudo sobre a identidade cultural da cidade de São Paulo. Caderno Virtual de Turismo. Rio de Janeiro, v. 16, n. 1, p. 32-45, abr. 2016.

REALIZAÇÃO

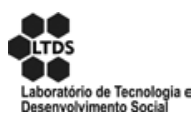

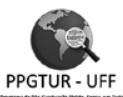

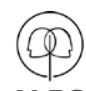

APOIO INSTITUCIONAL

EDIÇÃO

PATROCÍNIO

COPPE

UFR]

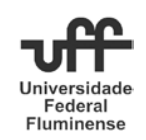

IPBS 


\section{RESUMO}

Este estudo é uma primeira exploração, ainda não profunda, sobre a natureza diversa das identidades da cidade de São Paulo, assumindo-as como dinâmicas e abertas, não fixas e não permanentes, caracterizadas pela multiplicidade, entendidas como obras em construção. Como cidade global, São Paulo possui múltiplas identidades; diante da ausência de referenciais estáveis, analisou-se sua narrativa identitária, que pode ser apreendida na história, na literatura, na música, nos meios de comunicação, na cultura popular, que assumem o papel de indícios, permitindo captar como a cidade é imaginada, descrita e apresentada. Na perspectiva histórica, a identidade da cidade foi vinculada à velocidade, ao trabalho e ao progresso, caracterizada como centro financeiro e industrial do País. Porém, em São Paulo o entretenimento vem ganhando relevância econômica, espaço nos meios de comunicação, tornando-se importante empreendimento econômico, meio de sua promoção turística, por fim, ao compor suas narrativas identitárias, podendo ser considerado no tempo presente como mais um elemento da identidade cultural da cidade de São Paulo.

Palavras-chave: Entretenimento. Lazer. Turismo.

\section{ABSTRACT}

This study is a first exploration, on the diverse nature of the identities of São Paulo, assuming it is dynamic and open, not fixed and not permanent, characterized by its multiplicity, and perceived as a work in progress. In order to grasp the city's multiple identities, and in view of the absence of solid references, this study analyzed its narrative identity, which can be apprehended in its history, literature, music, in the media, and in popular culture. Such elements have assumed the role of evidence and they allow us to grasp how the city is imagined, described, and shown, thus revealing its multiple identities. In a historical perspective, the city's identity has been linked to speed, work, and progress, as the city is characterized as a financial and industrial center in the country. However, entertainment in São Paulo has been gaining economic relevance and space in the media over the past decades, and it has become an important economic enterprise and a means to promote tourism in the city. It eventually started to compose the city's identitarian narrative and might even be considered an extra element comprising the cultural identity of the city of São Paulo nowadays.

Keywords: Entertainment. Leisure. Tourism.

\section{RESUMEN}

Este estudio es una primera explicación de la diversidad de las identidades de São Paulo, tomándola como lo más abierta y dinámica, no fija y no permanente, que se caracteriza por la multiplicidad, entendida como un trabajo en progreso. Para capturar las múltiples identidades de la ciudad, en la ausencia de referencias estables, se analizó su narrativa de identidad, que puede ser percibida en la historia, la literatura, la música, los medios de comunicación y la cultura popular, que asumen el papel de las pruebas, lo que permite la captura de cómo se imagina, designa y presenta la ciudad, dejando al descubierto sus múltiples identidades. Bajo una perspectiva histórica, la identidad de la ciudad fue atada a la velocidad, al trabajo y al progreso, pues se caracteriza como centro financiero e industrial del país. Sin embargo, en São Paulo en los últimos decenios, el entretenimiento está ganando espacio y relevancia económica en los medios de comunicación, por lo que es una empresa económica importante, a través de su promoción turística, lo que compone, por fin, su identidad narrativa y se puede considerar en la actualidad como otro aspecto de la identidad cultural de la ciudad de São Paulo.

Palavras clave: Entretenimiento. Ocio. Turismo. 


\section{Introdução}

O presente estudo tem seu ponto de partida na percepção de um significativo crescimento das atividades de entretenimento na cidade de São Paulo nos últimos anos, particularmente as relacionadas à gastronomia, bares, cinemas, teatros e casas noturnas. Segundo a Associação Brasileira de Bares e Restaurantes - Abrasel e a São Paulo Turismo - Spturis ${ }^{1}$, empresa municipal de promoção do turismo e eventos, a cidade possui 12,5 mil restaurantes, 16 mil bares, 260 salas de cinema, 181 teatros, com cerca de 600 peças encenadas por ano - destas pelo menos dez são versões nacionais de musicais da Broadway -, 2 mil casas noturnas e incontáveis eventos culturais variados, o que faz de São Paulo a segunda cidade do mundo com maior número de estabelecimentos do gênero, ficando atrás apenas de Nova Iorque (SÃO PAULO, 2010).

As atividades de entretenimento ao longo da história da cidade de São Paulo tornaram-se tão significativas, que foram incorporadas ao imaginário de seus habitantes, merecendo atenção da academia, estabelecendo relações sociais diferenciadas, formas próprias de ocupação e fruição do espaço urbano (MAGNANI, 2007), tornando-se um setor com grande peso na economia da cidade. É possível, no tempo presente, afirmar que atividades de entretenimento estão sendo incorporadas aos hábitos e costumes de um número crescente de paulistanos, tornando-se mais um componente da identidade cultural e da narrativa identitária da cidade, que é contada e recontada na história e na literatura paulistana, na mídia e na cultura popular, fornecendo uma série de histórias, imagens, panoramas, cenários, eventos históricos, símbolos e rituais que representam as experiências partilhadas e que dão sentido à cidade e à sua identidade (HALL, 2006).

Diante do exposto, este estudo investiga, como problema de pesquisa, se a identidade cultural de São Paulo está em pleno processo de transformação, incluindo o entretenimento como mais um elemento de sua identidade cultural compondo sua narrativa identitária.

Identidade historicamente centrada na imagem de cidade cosmopolita, com ênfase em seu poder industrial, caracterizada pela velocidade, pelo trabalho e pelo progresso (SALIBA, 2004). Indícios dessa identidade não faltam. São Paulo foi, devido a seu parque industrial, definida por seus cronistas como a "Locomotiva do Brasil", a "Chicago da América Latina", a "cidade não desperta, apenas acerta sua posição"2, do paulistano que só sabe trabalhar, da cidade que nunca dorme.

A identidade da cidade industrial, da velocidade, do trabalho e do progresso vem sendo alterada, agregando mais um elemento à sua identidade cultural, relacionado ao entretenimento, que agora compõe sua narrativa identitária. Seus cronistas contemporâneos ambientam suas histórias nos espaços de entretenimento e contam a vida de seus frequentadores. O cinema, o teatro, as novelas e as músicas baseiam seus enredos e letras nos acontecimentos dos bares, restaurantes, casas noturnas, e respectivos personagens em seus habitués ${ }^{3}$.

Jornais, revistas, emissoras de rádio e televisão possuem seções especializadas e jornalistas exclusivos para a cobertura das opções de entretenimento em São Paulo. Sites de internet sobre o entretenimento na cidade são impossíveis de ser contabilizados. Aplicativos para smartphones (apps) descrevem, classificam

1 Disponível em: 〈http://www.cidadedesaopaulo.com/sp/br/sao-paulo-em-numeros〉. Acesso em: 11 mar. 2012.

2 Sinfonia Paulistana, retrato de uma cidade de Billy Blanco (1974). Música utilizada como vinheta de programa matinal da Rádio Panamericana.

3 Frequentadores assíduos. 
e localizam restaurantes, teatros, cinemas e casas noturnas na cidade. $\mathrm{E}$ até mesmo as empresas públicas e privadas de promoção turística, como a São Paulo Turismo e a São Paulo Convention \& Visitors Bureau, destacam a variedade de possibilidades de entretenimento em São Paulo.

Essa nova forma de narrar a cidade demonstra uma mudança não apenas no perfil de sua economia, mas é um indício que pode fundamentar a hipótese de ser o entretenimento um componente dos hábitos e costumes de seus habitantes, a ponto de agregar mais um elemento à identidade cultural da cidade e à sua narrativa identitária, que, no tempo presente, é descrita como, além da cidade da indústria, da velocidade, do trabalho e do progresso, a cidade do entretenimento.

\section{Método}

O presente estudo é qualitativo, classificado como exploratório, por proporcionar maior familiaridade com os problemas de pesquisa, e descritivo, por ter como objetivo a descrição de características do fenômeno a ser compreendido (VEAL, 2011).

Para analisar as articulações do entretenimento na cidade de São Paulo, com suas narrativas, o estudo utilizou os métodos de pesquisas bibliográfica e documental, tendo como documentos, jornais, obras literárias e cinematográficas, letras de músicas e filmes, úteis para a compreensão de um processo ainda em curso ou para a reconstituição de uma situação passada.

\section{Breves considerações sobre o entretenimento}

O termo entretenimento, seu entendimento e significado contemporâneo, está vinculado ao empresariado norte-americano, referindo-se a atividades programadas quase sempre pagas, com o objetivo de simples diversão, distração, recreação (TRIGO, 2008, p. 25), reunidas em um mesmo fenômeno, porém, com características muito diferentes entre si, articuladas como mercadorias, com a finalidade de consumo especificamente caracterizado pela busca do prazer.

Esse grande e difuso grupo, que pode ser denominado entretenimento, possibilita transformar infinitas atividades em mercadoria para consumo, ou, como afirma Debord (2008), em espetáculo, desde as mais corriqueiras, populares e baratas às mais exclusivas, sofisticadas e caras.

Diferentes sociedades, ao longo de seu processo histórico de formação, parecem ter algum tipo de atividade divertida e programada em seus calendários religiosos e não religiosos, como brincadeiras de rua, jogos, festas, circos, teatros, shows, feiras, campeonatos, romarias, procissões e quermesses (TRIGO, 2008, p. 26). Mas foi apenas no século XX que o entretenimento adquiriu a característica de consumo em massa, por meio do cinema, rádio, televisão e, mais recentemente, com os computadores que, conectados entre si, formam a world wide web, reforçando a relação entre consumo de massa e entretenimento.

Ao apresentar suas considerações sobre entretenimento nesse período histórico, Gabler enfatiza:

[...] Eram gratificações e não edificações, transigência e não transcendência, reação e não contemplação, escape em vez de submissão às instruções morais. Como disse um elitista, a diferença entre entretenimento e arte é a diferença entre a "gratificação espúria e a experiência genuína como degrau para uma maior realização pessoal". [...] Um dos dogmas da cultura era que a arte exigia esforço para ser apreciada, sobretudo esforço intelectual, mas o entretenimento não fazia nenhuma exigência a seu público [...] trabalhava apenas a serviço dos sentidos e das emoções; era a reação passiva recompensada pela diversão. Operando sobre as emoções e sobre as vísceras, sobre os centros da 
irracionalidade e da irresponsabilidade, o entretenimento provocava reações excitando o sistema nervoso, quase da mesma forma que as drogas. De fato, era o entretenimento, e não a religião, como queria Marx, o ópio do povo (GABLER, 1999, p. 23-24).

É possível conjecturar que a postura preconceituosa de parte da intelectualidade diante da cultura de massa tenha fundamentos no argumento de Gabler aqui reproduzido. A aristocracia reacionária nunca aceitou que as camadas populares se divertissem fora do alcance da Corte, da Igreja e do Estado. Apenas as festas de exceção, como o carnaval, feiras populares e quermesses organizadas pela Igreja eram toleradas.

Ao se tornarem atividades independentes, lucrativas e orientadas pelos desejos do público, constituíram uma ameaça de perda, por parte das elites, de seu histórico poder para outras elites que estavam em pleno processo de formação, sem vínculos com o capitalismo industrial ou financeiro, mas com setores da atividade econômica, como a cultura de massa e o entretenimento.

$\mathrm{Na}$ origem latina da palavra entretenimento, estão inter, ou entre, e tenere, ou ter. Em sua evolução na língua inglesa, entertainment tem o sentido de "aquilo que diverte com distração ou recreação" e "um espetáculo público ou mostra destinada a interessar e divertir" (GABLER, 1999, p. 25), ou seja, os significados no latim ou no inglês estão atrelados à ideia de "ter entre". Enquanto a arte proporciona o ékstasis, do grego "deixar que saiamos de nós mesmos", proporcionando ao espectador a possibilidade de uma perspectiva fora dele, o entretenimento, ao contrário, induz o espectador para dentro dele e para dentro do próprio espectador, como uma negação à perspectiva. Portanto, "segundo os elitistas, enquanto a arte trata cada espectador, ouvinte ou leitor, como indivíduo, provocando uma resposta individual à obra, o entretenimento trata suas plateias como massa" (TRIGO, 2008, p. 32).

Não se pode ignorar a importância social, cultural e econômica do entretenimento na vida das pessoas. São vários os indícios que apontam como ele permeia a vida social, tornando-se uma força econômica, referência cultural e estilo em vários grupos sociais, devendo ser encarado como mais uma das diversas características definidoras das sociedades atuais e, como tal, um tema, apesar de recente, com potencial de ampliar a compreensão a respeito delas.

\section{A relevância do entretenimento para a cidade de são paulo}

O setor de entretenimento em São Paulo, como já afirmado, tornou-se um de seus elementos culturais identitários, refletindo em diferentes dimensões da vida da capital paulista, entre elas, destacam-se as seguintes:

\section{A relevância do entretenimento para a economia da cidade}

O mercado consumidor de entretenimento também é revelador da importância do setor para a cidade. Paulistanos, moradores da região metropolitana e do interior do Estado, frequentadores assíduos ou eventuais da cidade injetam milhões de reais na economia, constituindo de fato um mercado consumidor (D’ALESSIO, 2008).

De acordo com pesquisa realizada em conjunto pelo Datafolha e a Revista São Paulo, que entrevistou 807 pessoas, entre os dias $1^{\circ}$ e 4 de março de 2012, sobre seus hábitos de lazer, relacionados apenas à fruição do entretenimento noturno na cidade, o gasto médio de uma pessoa na noite paulistana é de R\$ 109,70 , sendo que $28 \%$ gastam até $R \$ 50,00,42 \%$ entre $R \$ 50,00$ e $R \$ 100,00,16 \%$ entre $R \$ 100,00$ e $R \$$ 
150,00 e $14 \%$ chegam a gastar mais de $\mathrm{R} \$ 150,00$, índice que sobe para $42 \%$, entre os que saem todas as noites, e para $27 \%$ entre os casados. Um exemplo citado na pesquisa é do nutricionista Lucas Ferraz, de 24 anos, que sai três vezes por semana.

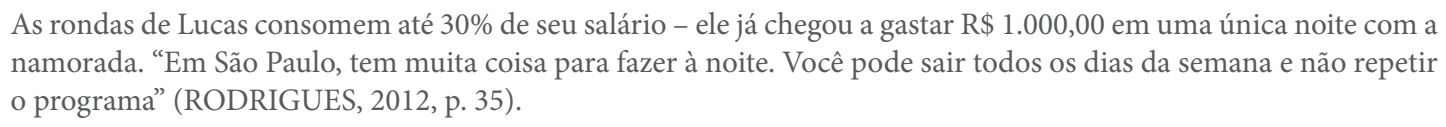

Pessoas como Lucas não são incomuns em São Paulo. Segundo a mesma pesquisa, o faturamento de restaurantes, bares e casas noturnas cresceu 15\% entre os anos de 2009 e 2010. Segundo a Associação Brasileira de Bares e Restaurantes (Abrasel), o montante passou de R \$ 37,5 milhões para R 46 milhões.

Os números relacionados à economia do entretenimento reforçam seu significado para a cidade de São Paulo. Desenvolveu-se uma indústria que emprega diretamente em suas atividades milhares de pessoas, outras tantas em suas atividades satélites, como logística, treinamento e formação de mão de obra, moda, construção civil, decoração, comunicação, estendendo a cadeia econômica para muito além das atividades de entretenimento (MIRANDA, 2002, p. 33). Somente o setor de restaurantes, segundo a Abrasel, emprega cerca de 780 mil pessoas, o que faz deste um dos maiores geradores de empregos da cidade.

\section{A relevância do entretenimento a partir dos meios de comunicação}

Respondendo ao crescimento que os números acima demonstram, os meios de comunicação dedicam considerável espaço e tempo ao entretenimento. Os jornais de grande circulação, como Folha de São Paulo e O Estado de São Paulo, possuem cadernos especializados no tema. A Folha de São Paulo, além de seu caderno Folha Ilustrada, com frequência diária, encarta às sextas-feiras o Guia Folha e, aos domingos, a Revista São Paulo, com informações sobre as possibilidades de entretenimento da capital paulista. Revistas semanais de circulação nacional, como Veja e Época, possuem encartes em forma de revista, denominadas, respectivamente, Veja São Paulo e Época São Paulo, que também tratam das opções de entretenimento na cidade.

A gastronomia em São Paulo pode ser considerada uma forma de entretenimento, prova disso é o fato de a Veja São Paulo lançar anualmente, no mês de setembro, uma edição especial dedicada à gastronomia da cidade, chamada "Comer e Beber", dividida em seções com comidinhas, bares, restaurantes e vinhos. Em 1997, ano de sua primeira edição, a revista foi lançada com 172 páginas, apresentando 350 restaurantes e 100 bares. Em sua última edição (2013/2014), foram 548 páginas, que apresentam detalhadamente 1.268 endereços, de pastel de feira aos requintados restaurantes de alta cozinha ${ }^{4}$.

Tais números dão a medida da importância da gastronomia como entretenimento na cidade. São também indícios do que é hoje conteúdo presente e obrigatório em todos os jornais e revistas de grande circulação, independente de sua especialização ou segmentação. Em São Paulo, as opções de entretenimento tornaram-se informações indispensáveis, demonstrando como sua fruição está incorporada aos hábitos e costumes do paulistano.

As emissoras de rádio e televisão não fogem à regra. Rádios com programação dedicada à música ou exclusivamente a notícias possuem boletins diários sobre entretenimento. Dois exemplos são as rádios Central Brasileira de Notícias (CBN) e Bandeirantes News (Band News), que possuem colunistas especia-

4 Disponível em: 〈http://vejabrasil.abril.com.br/portal/〉. Acesso em: 19 fev. 2013. 
lizados no tema e boletins segmentados em cinema, teatro, restaurantes, casas noturnas e espetáculos, que procuram manter os ouvintes informados sobre as possibilidades de entretenimento da cidade.

Já a internet é espaço de muitos websites, blogs e vlogs (vídeo blogs) sobre o tema. Os meios de comunicação já citados possuem em suas versões on-line páginas dedicadas ao entretenimento. Um website paulistano com conteúdo totalmente dedicado ao tema é o "Uia Diário". Tal site merece destaque não apenas por ser pioneiro (no ar desde 2008), mas por ser um guia on-line de entretenimento que tem como diferencial um amplo serviço de informações sobre shows, exposições, teatro, cinema, restaurantes, festas e eventos culturais na capital paulista, diariamente.

Aplicativos para smartphones, os chamados apps, são outros bons indícios da importância do setor de entretenimento para a cidade. Possuindo funções tão diversificadas que é impossível elencá-las. Os apps com funções de entretenimento ou para sua promoção são muito populares, ocupando os primeiros lugares em downloads. O entretenimento em São Paulo é tema de 24 apps, que podem ser divididos em dois grupos.

No primeiro grupo, estão apps dedicados ao turismo na cidade de São Paulo. O segundo grupo é formado por apps que tratam especificamente de restaurantes, bares, cinemas, teatros e casas noturnas. Todos eles possuem funcionalidades, como sistema de busca e mapa de localização geográfica, que traça rotas a partir da localização do usuário até o estabelecimento desejado, por ônibus, carro ou a pé. Em seu texto de apresentação, o app "São Paulo é tudo de bom", produzido pela São Paulo Convention \& Visitors Bureau, a cidade é descrita por suas possibilidades de experiências variadas de entretenimento, que vão da gastronomia à vida noturna.

Já o texto que descreve o app "SP Mobile", da Spturis, afirma ter como objetivo posicionar e promover a cidade de São Paulo como a capital dos negócios, conhecimento e entretenimento da América Latina, destacando seu caráter vanguardista e cultural. Entre suas funcionalidades estão seções, como "Comes e bebes", que indicam e descrevem bares, restaurantes e "Entretenimento" - baladas, cinemas e teatros.

Para além dos expressivos números de apps que tratam do tema, é preciso destacar que alguns deles estão entre os mais baixados das lojas virtuais. O $a p p$ "Veja Comer e Beber", que apesar do nome não trata apenas de bares e restaurantes, mas também de casas noturnas, é um dos aplicativos mais baixados no Brasil. Desde seu lançamento em abril de 2010, ao custo de US\$ 2.99, com, em média, 55 mil downloads por mês, figura na lista dos 25 apps mais baixados na Apple Store Brasil, ficando em primeiro lugar, por dias, todas as vezes que são lançadas atualizações ${ }^{5}$.

Tais dados são muito significativos, fornecem uma medida objetiva da importância dessas atividades nos hábitos e costumes dos paulistanos, demonstrando o tamanho da demanda pela fruição do entretenimento.

\section{A relevância do entretenimento como empreendimento econômico}

A análise dos empreendimentos de entretenimento, particularmente os relacionados à noite, fornece números que reforçam a relevância do entretenimento para a cidade de São Paulo.

5 Veja Comer e Beber. Disponível em: 〈http://www.publiabril.com.br/upload/files/oooo/0751/App_VEJA_Comer_e_Beber_mar12. pdf $>$. Acesso em: 03 mai. 2012. 
Empresários investem somas significativas em entretenimento noturno, obtendo retornos expressivos. Exemplos não faltam. O grupo Clash, constituído em 2008, iniciou suas atividades com a casa noturna Clash, na Barra Funda, com investimento de R 1 milhão e faturamento de R 3 milhões. O grupo, nos últimos anos, inaugurou três novas casas: o clube Lab, na região da Rua Augusta, o restaurante espanhol Donostia, em Pinheiros, e uma lanchonete na Rua Augusta. Os lucros do grupo, incluindo os serviços de catering e o aluguel dos espaços para a promoção de eventos especiais, somaram em 2011 cerca de R 11 milhões (RODRIGUES, 2012, p. 35).

Outro grupo de 43 investidores criou a empresa A.Life Entertainment Group, especializada em casas noturnas luxuosas, que faturam R $\$ 75$ milhões por ano, atendendo 70 mil pessoas por mês (LOMBARDI, 2012). Com números semelhantes, destaca-se a casa noturna Pink Elephant, com investimento de $\mathrm{R} \$ 5$ milhões, funcionou por dois anos, e o faturamento mensal oscilou entre R \$300 mil e R \$ 2 milhões.

O setor de entretenimento paulistano tornou-se, como fica evidente nos exemplos anteriores, ótimo negócio. Originando empresários que fizeram carreira, empreendendo exclusivamente no entretenimento. Um exemplo é José Victor Oliva que, em 1979, com 23 anos, criou, além do Gallery, ícone da noite paulista por 28 anos, casas noturnas como o Banana Café, Moinho Santo Antônio e Resumo da Ópera, sendo conhecido como "rei da noite". Hoje tal status pertence a Facundo Guerra, denominado por reportagem da Revista Veja São Paulo como "o novo reizinho da noite":

Dentro da riquíssima galeria de personagens que fizeram e fazem sucesso agitando a noite paulistana, Facundo Guerra, um argentino nascido em Córdoba e radicado no Brasil desde 1976, já merece um capítulo exclusivo. Ele entrou no ramo por acaso, depois de perder o emprego de executivo que lhe rendia um salário mensal de 10.000 reais e de uma tentativa frustrada de se associar a uma marca de roupas. Mesmo sem experiência no mercado da boemia, topou o convite de um amigo para virar sócio de uma boate construída dentro de um galpão de 400 metros quadrados onde funcionava uma oficina de carros, na parte central da Rua Augusta, ao lado de inferninhos, hotéis de alta rotatividade e botecos vagabundos (GIOVANELLI, 2011).

Facundo Guerra, que emprega 90 funcionários diretos e 210 indiretos, fez outros investimentos que, somados, chegam a R \$1,4 milhão, como os bares Z Carniceria, na própria Rua Augusta, e Volt, na Rua Haddock Lobo; as casas noturnas Lions, na Avenida Brigadeiro Luís Antônio e a Yatche, no Bixiga, além da casa de espetáculos Cine Joia, no bairro da Liberdade. Em julho de 2011, o público mensal de seus negócios chegava à metade das 60 mil pessoas que frequentam as principais casas noturnas da cidade: Clash, D-Edge, Estúdio Emme, Disco e Kiss \& Fly.

Assim como o Gallery de seu antecessor, a casa noturna Vegas, de Facundo Guerra, fez história, sendo inclusive apontada como desencadeadora da revitalização do degradado Baixo Augusta, tradicional região boêmia localizada entre a Avenida Paulista, Rua Augusta, Praça Roosevelt e Rua da Consolação. Região que hoje é um polo de entretenimento, somando, entre bares, restaurantes, cinemas, teatros e casas noturnas, cinquenta estabelecimentos.

Um efeito dessa revitalização é que, após 25 anos, a Rua Augusta recebe o lançamento de dois condomínios residenciais, um deles com cerca de 200 apartamentos, com metro quadrado estimado, ainda no lançamento do empreendimento, em $\mathrm{R} \$ 15$ mil, valor próximo ao de bairros residenciais tradicionais como Moema e Pinheiros. 
A região está sofrendo um processo de gentrificação ${ }^{6}$, como aconteceu com o Soho, em Nova Iorque, que recebeu, em um curto espaço de tempo, jovens artistas, valorizando o bairro até que não mais pudessem viver nele, pelo alto custo. Fenômeno que se repete na Vila Madalena. Nos anos 1970 e 1980, a região atraiu jovens devido à sua vida boêmia e cultural, fato que a valorizou, gerando o encarecimento dos aluguéis e a consequente mudança do perfil de seus moradores. O Baixo Augusta segue essa tendência e, em cinco anos, como prevê Facundo Guerra, a região ficará mais residencial, mais parecida com os Jardins.

\title{
A relevância do entretenimento para a promoção turística da cidade
}

Uma consequência do crescimento do setor de entretenimento em São Paulo foi a sua transformação em atrativo turístico. Hoje ele é parte obrigatória do roteiro de visitação dos que vão a São Paulo a negócio ou a lazer. Surge o turismo com motivação na fruição do entretenimento, um público cada vez maior, vindo das cidades do interior de São Paulo e de outros Estados brasileiros, desejoso em conhecer o que suas cidades não oferecem.

Agências de turismo desenvolveram pacotes para esse público, conjugando hospedagem em hotéis de luxo, com todos os seus serviços, ingressos para peças de teatros, musicais, exposições, shows variados, reservas em restaurantes sofisticados e acesso privilegiado às casas noturnas mais concorridas. A Blumar Turismo e Viagens, por exemplo, sediada na cidade do Rio de Janeiro, oferece o pacote "Conheça São Paulo". No texto de apresentação do pacote, a cidade é redefinida não mais apenas como a cidade do trabalho, sua identificação tradicional, mas por seus atrativos de entretenimento:

\begin{abstract}
A capital do Estado de São Paulo é o mais importante e dinâmico polo econômico da América Latina. São Paulo é uma cidade cosmopolita famosa por sua diversidade étnica e vida agitada. Mas, se engana quem pensa que em São Paulo só se vive para o trabalho. A cidade oferece excelentes opções de lazer e cultura para se aproveitar de dia ou à noite. São Paulo é uma cidade com diversas atrações que vão desde passeios culturais a compras. Outro ponto importante da cidade são os sofisticados restaurantes, São Paulo é reconhecido como um dos maiores e melhores polos gastronômicos do País. A vida noturna é bem agitada e com diversas opções para todos os gostos, diversos barzinhos, restaurantes e boates ${ }^{7}$.
\end{abstract}

A apresentação conta ainda com descrições específicas dos atrativos, que são divididos nos seguintes links: Arte e Cultura; Onde Comer; Natureza e Esportes; Vida Noturna; Compras e Atrações Turísticas. Nos textos dos atrativos Onde Comer e Vida Noturna, a cidade é definida como o melhor polo gastronômico do País, e os restaurantes são convertidos em atrações turísticas. A vida noturna aparece como agitada e diversificada, destacando a variedade de bares e casas noturnas.

Seguindo essa tendência, hotéis da cidade oferecem estadias diferenciadas aos finais de semana, quando a ocupação é menor. O Hotel Meliá e o InterContinental oferecem pacotes que incluem peças em cartaz nas proximidades. O Renaissance São Paulo Hotel disponibiliza em suas ofertas e promoções três que são fundamentadas nas possibilidades de fruição das opções de entretenimento da cidade ${ }^{8}$. A primeira, denominada Stretch Your Weekend Package no Renaissance São Paulo Hotel, apresenta assim São Paulo: "A maior cidade da América Latina se torna muito mais viva aos finais de semana". A segunda oferta é o Taste of São Paulo, em que a gastronomia é a protagonista: "Sabores de todo o mundo, com a autenticidade de

60 neologismo "gentrification” foi criado em 1964 pela socióloga inglesa Ruth Glass, para definir a valorização imobiliária de bairros degradados de Londres, devido a intervenções governamentais e não governamentais, resultando em um enobrecimento urbano (BERNHARDT, s.d.).

7 Disponível em: 〈http://www.blumar.com.br/cidades.cfm?cidade=sa0\%2opaulo〉. Acesso em: 15 mai. 2012.

8 Disponível em: 〈http://hoteis.marriott.com.br/hotels/hotel-deals/saobr-renaissance-sao-paulo-hotel/index.asp〉. Acesso em: 15 mai. 2012. 
nossa cidade. Surpreenda-se!" A terceira, Renaissance On The Stage, em que o teatro é o destaque: "Entre em cena para conhecer o melhor de São Paulo. Aproveite o espetáculo!"

Tais ofertas e promoções criaram uma nova forma de paulistanos e paulistanas fruírem a cidade, transformando-se em turistas. Os moradores da capital já são 6,8\% do total de hóspedes, segundo levantamento feito no segundo semestre de 2011 pela Spturis. Dois anos antes esse número não ultrapassava 3\%.

Sensível ao fenômeno, a Folha de São Paulo investigou o assunto e, em reportagem publicada em 13 de janeiro de 2012, apresentou dados significativos, em que o entretenimento é um dos elementos desencadeadores da ocupação dos hotéis ${ }^{9}$. Citado pela reportagem, Toni Sando, diretor da São Paulo Convention \& Visitors Bureau, empresa que reúne vários segmentos do setor turístico, destaca as possibilidades de entretenimento da cidade: "O fim de semana em São Paulo tem programação intensa, boa gastronomia, espetáculos que vieram da Broadway”. De acordo com ele, a demanda acaba atraindo quem mora longe dos polos culturais e gastronômicos da cidade, concentrados nas zonas oeste e central, onde também estão localizados hotéis de alto padrão com esse tipo de pacote. "É gente que mora afastada do centro e quer se sentir turista sem pegar a estrada”.

A Spturis, empresa de turismo e eventos de São Paulo, que tem como sócia majoritária a Prefeitura, visando promover a cidade como polo de turismo de negócios, tem utilizado o entretenimento para representar e apresentar a cidade. Um indício da importância do setor de entretenimento na promoção turística da cidade é a existência de uma diretoria exclusiva para o entretenimento, que destaca ser a cidade não apenas um destino de turismo de negócios, enfatizando sua oferta de cultura, gastronomia e entretenimento:
A Diretoria de Turismo e Entretenimento atua na consolidação nacional e internacional da cidade como destino turístico. Para isso planeja e implanta projetos de estruturação da oferta turística, além de desenvolver ações de promoção, marketing e divulgação, com o objetivo de qualificar São Paulo como uma cidade cosmopolita, cultural, gastronômica e rica em entretenimento, o que a capacita para não apenas ser um grande destino de turismo de negócios ${ }^{10}$.

A diretoria ainda conta com uma Gerência de Promoção Turística e Entretenimento e uma Coordenadoria de Promoção de Turismo de Lazer e Entretenimento. Para Luciane Leite, diretora de Turismo e Entretenimento da Spturis, visitantes a negócio e turistas aumentam as já longas filas das casas noturnas e restaurantes da cidade. Hoje, um dos fatores que motivam os visitantes a estenderem sua estadia em São Paulo é a oferta de entretenimento. Tendência que vem sendo detectada há cinco anos por pesquisa realizada pela Spturis sobre esse comportamento. Em 2011, 21\% dos visitantes e turistas optaram por ficar mais algum tempo na cidade para ir a casas noturnas e $17 \%$ para conhecer os restaurantes. De acordo com Luciane Leite,

para nosso trabalho de promoção, os restaurantes e as casas noturnas são fundamentais. Aqui, há do eletrônico ao sertanejo, de botecos supertradicionais a restaurantes de reconhecimento internacional. É o grande diferencial da cidade (apud RODRIGUES, 2012, p. 35).

Outro exemplo da relevância do entretenimento para o turismo em São Paulo é a Virada Cultural. Inspirada na Nuit Blanche parisiense, tem como um de seus objetivos a promoção turística da cidade e sua

\footnotetext{
9 Disponível em: 〈http://www1.folha.uol.com.br/saopaulo/1032576-tarifas-menores-atraem-paulistanos-para-hoteis-nos-fins-de-semana.shtml>. Acesso em: 15 mai. 2012.

10 Disponível em: 〈http://www.spturis.com/v7/equipe-turismo.php〉. Acesso em: 15 mai. 2012.
} 
conversão em metrópole internacional ${ }^{11}$. O evento promovido desde 2005 pela Prefeitura da cidade de São Paulo, com 24 horas ininterruptas, conta com eventos culturais dos mais variados tipos, como espetáculos musicais, peças de teatro, exposições de arte e história, entre outros. Durante a edição 2011 da Virada Cultural, foi realizada uma pesquisa para identificar o perfil socioeconômico do público presente e também obter uma avaliação geral da cidade e do megaevento.

Coordenada pela equipe do Observatório de Turismo da Spturis, a pesquisa aplicou 2.042 questionários e mostrou que 9,7\% do público são pessoas de fora da cidade, sendo 99,4\% desses visitantes de outros Estados brasileiros, principalmente do Rio de Janeiro, Santa Catarina, Minas Gerais e Bahia, e também do interior do Estado de São Paulo (cidades como Campinas, Limeira, Jundiaí, Sorocaba e Bragança Paulista), que permanecem na cidade por cerca de três dias e gastam, em média, $\mathrm{R} \$ 1.088,00$.

O mesmo pode-se dizer do programa "Fique Mais Um Dia", da Spturis, que incentiva os turistas de negócio a estender sua estadia na cidade. O site do programa e seu caderno de divulgação enfatizam as possibilidades de entretenimento na cidade. Na capa do caderno, aparecem as frases: "São Paulo Fique mais um dia; Onde ficar, comer e se divertir: viva tudo o que a cidade tem de melhor; Passeios, Compras, Cultura, Lazer ao ar livre, Baladas, Programas para as crianças".

Em texto que o ex-prefeito Gilberto Kassab apresenta o programa, a cidade é descrita como um grande centro de entretenimento, a exemplo de Nova Iorque e Londres, com todas as facilidades das capitais europeias, com os melhores restaurantes, hotéis, cinemas e museus. Por fim, o prefeito convida: "ao chegar à cidade para fechar um negócio, fazer uma reunião ou participar de um evento, fique ao menos mais um dia e desfrute de todo esse universo de lazer. São Paulo está a sua disposição: aproveite."

No website YouTube, a Spturis possuiu um canal que compila os vídeos de diferentes origens, como programas de televisão, reportagens jornalísticas e vídeos institucionais próprios, abordando temas relacionados ao turismo na cidade. A análise desses vídeos revela a importância do setor de entretenimento, com sua gastronomia, espetáculos teatrais, shows, exposições e casas noturnas, para a promoção da cidade. Dos 157 vídeos postados no canal, quase a totalidade faz referência ao entretenimento. Mais especificamente, os vídeos institucionais, aqueles produzidos sob encomenda e orientação da Spturis, utilizam as possibilidades de entretenimento como meio de promoção turística. Tais vídeos são indícios que reforçam a importância do entretenimento como mais um elemento da identidade cultural de São Paulo.

Um exemplo são os vídeos da campanha Unimaginable, criada em 2010 pela agência Lew’Lara\TBWA para Spturis ${ }^{12}$. Personalidades paulistas, conhecidas dentro e fora do País, mostram seus talentos, tendo a cidade de São Paulo como inspiração: Alex Atala desenvolve um novo prato, DJ Marky produz a trilha, os irmãos Campana criam o design de uma poltrona, Hornest idealiza personagens nos muros da cidade; todas essas expressões juntas, com a produção executiva de Fernando Meirelles e direção de Paulinho Caruso. No vídeo "Encontre-se em São Paulo", da mesma campanha, a protagonista, uma turista, passeia por pontos turísticos da cidade, como a Pinacoteca, a Estação Luz, o Mercado da Cantareira, o Masp, o Estádio do Pacaembu, uma loja de decoração, um bar com música ao vivo, durante o dia, e outros durante a noite, como sala São Paulo, ponte estaiada Octávio Frias de Oliveira, Teatro do Ibirapuera, um restaurante sofisticado e uma casa noturna, onde a protagonista encerra a noite dançando ${ }^{13}$.

\footnotetext{
11 Disponível em: 〈http://spturis.com/v7/noticia.php?id=169〉. Acesso em: 31 mai. 2012. 12 Disponível em: 〈http://ccsp.com.br/ultimas/noticia.php?id=49855〉. Acesso em: 17 mai. 2012. 13 Disponível em: 〈http://www.youtube.com/watch?v=BG8hrsE992E\&feature=plcp〉. Acesso em: 17 mai. 2012.
} 


\section{0 entretenimento e a identidade cultural da cidade}

A arte também fornece indícios sobre a importância do entretenimento para a formação da identidade cultural da cidade. Nesse sentido, apenas para exemplificar essa afirmação, e sem a pretensão de produzir aqui um estudo profundo, a análise do seriado "Alice" revela o crescimento da importância do entretenimento no modo de vida de uma parcela dos paulistanos; já a produção musical de Adoniran Barbosa demonstra de forma crítica que a cidade de São Paulo foi historicamente identificada com o trabalho, velocidade e progresso. Tal mudança na identidade da cidade também pode ser captada por meio da literatura, por exemplo, na obra do escritor paulistano Daniel Piza, Noites Urbanas, em que o tempo e os locais de lazer não são apenas indícios da identidade cultural de São Paulo, mas relevam os sentimentos e emoções de seus moradores, representados pelos personagens do livro.

Entre as muitas obras cinematográficas, em que a cidade de São Paulo é cenário, destaca-se como exemplo do entretenimento incorporado à identidade cultural da cidade, o seriado (no formato telefilme) "Alice", com 13 episódios em 2008 e mais dois filmes de 90 minutos exibidos em 2010. Produzido pela Home Box Office (HBO) e Gullane Filmes, foi dirigido e roteirizado por Sérgio Machado e Karim Aïnouz. O seriado narra a história de Alice, representada pela atriz Andreia Horta, que levava uma vida pacata como guia turístico em Palmas, Tocantins, quando é obrigada a viajar para São Paulo, sua cidade natal, para resolver problemas decorrentes do processo de partilha da herança deixada pelo pai. A viagem seria breve, mas Alice se encanta com a cidade, particularmente com suas opções de entretenimento e decide ficar.

Grande parte do seriado é ambientado em restaurantes, bares, cinemas, teatros, shows, exposições, casas noturnas que cumprem o papel de País das Maravilhas para a Alice paulistana. Os diretores escolheram como personagens os habitués desses lugares. Para Aïnouz, a história é um tipo de crônica, pois relata o dia a dia dos personagens típicos da cidade de São Paulo. "Como eles trabalham, como acordam, como dormem, como é a vida cotidiana deles. E isso tudo se mistura às aventuras que se pode viver em uma cidade como São Paulo."

A música também revela os elementos e as imagens que simbolizam e representam a cidade, dando sentido à sua identidade cultural (HALL, 2006). Um compositor em particular, Adoniran Barbosa, exemplifica, por meio de suas canções, a importância do entretenimento, particularmente o relacionado à vida noturna em São Paulo, nas décadas de 1950 e 1970, que se transformava física e culturalmente. No momento em que o trabalho, a velocidade e o progresso eram componentes predominantes na identidade da cidade, o entretenimento já

[...] exercia certo fascínio sobre as pessoas; era uma maneira de fuga das mazelas, de experimentar prazeres, de fugir do cotidiano cansativo e monótono da cidade. A vida boêmia, a efervescência cultural nos bares e botequins de São Paulo, tentava diminuir o ritmo que a cidade impunha aos seus moradores (SANTOS e DENCKER, 2008, p. 21).

A obra de Adoniran Barbosa é uma narrativa da cidade que percorre várias épocas, principalmente a da São Paulo industrial, relatando as mudanças dos hábitos e costumes, descrevendo rituais e tradições de seus habitantes, destacando os traços e as singularidades da identidade cultural paulistana. Suas músicas ironizam o tão exaltado progresso, delatando as dificuldades dos que assistiam aos símbolos da cidade ou apenas a uma pobre, mas "Saudosa Maloca", sendo destruídos sob a justificativa da necessidade de modernização. 
Modernização que construía a cidade da velocidade, projetada para não parar, alertando para o desaparecimento da cidade pacata e o surgimento de uma cidade violenta e insegura (SANTOS e DENCKER, 2008, p. 24-5), como denuncia "Iracema": Iracema, fartavam vinte dias pra o nosso casamento / Que nóis ia se casar / Você atravessou a São João / Veio um carro, te pega e te pincha no chão.

O trabalho, que gerava o progresso, aparece em muitas de suas músicas como monótono e estafante, sendo satirizado. Em "Conselho de Mulher", Deus parece concordar com o boêmio paulistano: Eu sempre iscuitei falar, que o pogressio vem do trabaio / Então amanhã cedo, nóis vai trabalhar / Quanto tempo nóis perdeu na boemia / Sambando noite e dia, cortando uma rama sem parar / Agora iscuitando o conselho das mulheres / Amanhã vou trabalhar, se Deus quiser, mas Deus não quer! [...]

Sua crítica à cidade do trabalho, da velocidade e do progresso usou a ruptura possibilitada pelo entretenimento, pela vida noturna, pelos hábitos dos boêmios, pela bebida, tema recorrente em suas letras - [...] Não me amole rapaz, não me amole / Não me amole, deixa de conversa mole / Agora não é hora de falar / Nós viemo aqui pra beber ou pra conversá? [...] - pela festa, pela roda de samba. As comemorações, os encontros, enfim, a sociabilidade engendrada nos espaços de entretenimento, como acontecia "No Morro da Casa Verde", contrapõem-se às amarguras da vida dos trabalhadores: Silêncio, é madrugada / No morro da casa verde / A raça dorme em paz / E lá embaixo / Meus colegas de maloca / Quando começa a sambá não para mais / Silêncio! / Valdir, vai buscar o tambor / Laércio, traz o agogô / Que o samba na casa verde enfezou! / Silêncio!

A literatura produzida em São Paulo também fornece indícios da importância do setor de entretenimento na identidade cultural da cidade. Como narrativa da cidade, a literatura capta o imaginário de sua população. Nela estão projetadas as fantasias, as emoções, os dramas que evidenciam a importância do entretenimento para sua identidade cultural.

Em 2010, o escritor paulistano Daniel Piza publicou o livro Noites Urbanas, com dez contos e dezoito minicontos, todos ambientados em São Paulo. Para o autor, cidade "é uma cornucópia de histórias ainda por contar"14, é o vaso repleto de personagens, situações, dramas, paixões, conflitos que inspiram músicos, escritores, cineastas e todos os cronistas que narram o cotidiano na metrópole paulista.

Piza produziu um sutil mapeamento dos sentimentos dos paulistanos, expressando-os por meio de analogias que revelam a indiferença, a frustração, o desamor e os múltiplos dilemas das pessoas que ao mesmo tempo odeiam e amam, aflorando tensões que geram simultaneamente a intensidade criativa e conflito social, vitalidade e melancolia. Não se trata apenas dos equipamentos e atividades de entretenimento como referência e cenário, ou como fonte para a criação de personagens e histórias. $\mathrm{O}$ autor usa as paisagens associadas às atividades de entretenimento da cidade como analogia para descrever os sentimentos de seus personagens, como se somente esse momento de lazer tivesse o poder de sintetizar com precisão e profundidade o que sentem os que vivem em São Paulo.

\section{Considerações finais}

Diante do exposto, parece impossível não considerar a importância econômica, social e cultural do setor do entretenimento para a compreensão complexa da cidade. Ele está incorporado aos hábitos e costumes dos paulistanos, promove São Paulo como destino turístico, gera trabalho, renda e riqueza, é enredo

14 Disponível em: 〈http://blogs.estadao.com.br/daniel-piza/convite-a-todos/〉. Acesso em: 28 mai. 2012. 
cinematográfico, inspira compositores e escritores. Os argumentos aqui apresentados apontam que a fruição de entretenimento é cada vez mais significativa no cotidiano da cidade e de uma parcela considerável de sua população, com uma história particular, transformando-se em setor de peso na economia da cidade e em uma referência capaz, no tempo presente, de ser mais um elemento da identidade cultural da cidade de São Paulo.

\section{Referências}

D’ALESSIO, P. São Paulo cidade espetáculo: metrópole da diversidade brasileira. São Paulo: Editora Dialeto, 2008.

DEBORD, G. A sociedade do espetáculo. Rio de Janeiro: Contraponto, 2008.

GABLER, N. Vida, o filme: como o entretenimento conquistou a realidade. São Paulo: Companhia das Letras, 1999.

GIOVANELLI, C. Nascimento e morte de uma balada. Revista Veja São Paulo, São Paulo, 10 ago. 2011. Disponível em: 〈http://vejasp.abril.com.br/revista/edicao-2229/nascimento-morte-de-umabaladà. Acesso em: 10 ago. 2011.

HALL, S. A identidade cultural na pós-modernidade. 11. ed. Rio de Janeiro: DP\&A, 2006.

LOMBARDI, M. Jovens deixam carreira em grandes empresas para investir em entretenimento. Universo On-Line, São Paulo, 21 set. 2012. UOL Economia. Disponível em: < http://economia.uol. com.br/ultimas-noticias/redacao/2011/09/21/jovens-deixam-carreira-em-grandes-empresas-parainvestir-em-entretenimento.jhtm>. Acesso em: 21 set. 2012.

MAGNANI, J. G. C.; SOUZA, B. M. (organizadores). Jovens na metrópole. Etnografias de circuitos de lazer, encontro e sociabilidade. São Paulo: Editora Terceiro Nome, 2007.

MIRANDA, J. M. Ciclos de produção e cadeias produtivas na cultura. In: PRESTES FILHO, L. C.; CAVALCANTI, M. C. Economia da cultura: a força da indústria cultural no Rio de Janeiro. Rio de Janeiro: E-papers, 2002.

PIZA, D. Noites Urbanas: contos. Rio de Janeiro: Bertrand Brasil, 2010.

RODRIGUES, L. Overnight. Folha de São Paulo, São Paulo, 15 abr. 2012. Revista São Paulo, p. 35.

SALIBA, E. T. Histórias, memórias, tramas e dramas da identidade paulistana. In: PORTA, P. (org.) História da cidade de São Paulo: a cidade na primeira metade do século XX. São Paulo: Paz e Terra, 2004. v. 3, p. 555-587.

SANTOS, L. O. S.; DENCKER, A. F. M. São Paulo dá samba: visão da hospitalidade por meio do olhar de Adoniran Barbosa. Revista Hospitalidade, São Paulo, ano V, n. 1, p. 13-30, jun. 2008.

SÃO PAULO. São Paulo Turismo. Plano de turismo municipal - cidade de São Paulo. São Paulo: Spturis/Prefeitura de São Paulo, 2010.

TRIGO, L. G. G. Entretenimento: uma crítica aberta. São Paulo: Editora Senac, 2008.

VEAL, A. J. Metodologia de pesquisa em lazer e turismo. São Paulo: Aleph, 2011. 